
UNDER CONTRACT DE-AC02-76CH03073

PPPL-3837

PPPL-3837

UC-70

Transport in Auxiliary Heated NSTX Discharges

by

B.P. LeBlanc, M.G. Bell, R.E. Bell, M.L. Bitter, C. Bourdelle, D.A. Gates, S.M. Kaye, R. Maingi, J.E. Menard, D.Mueller, M. Ono, S.F. Paul, M.H. Redi, A.L. Roquemore, A. Rosenberg, S.A. Sabbagh, D. Stutman, E.J. Synakowski, V.A. Soukhanovskii, and J.R. Wilson

July 2003
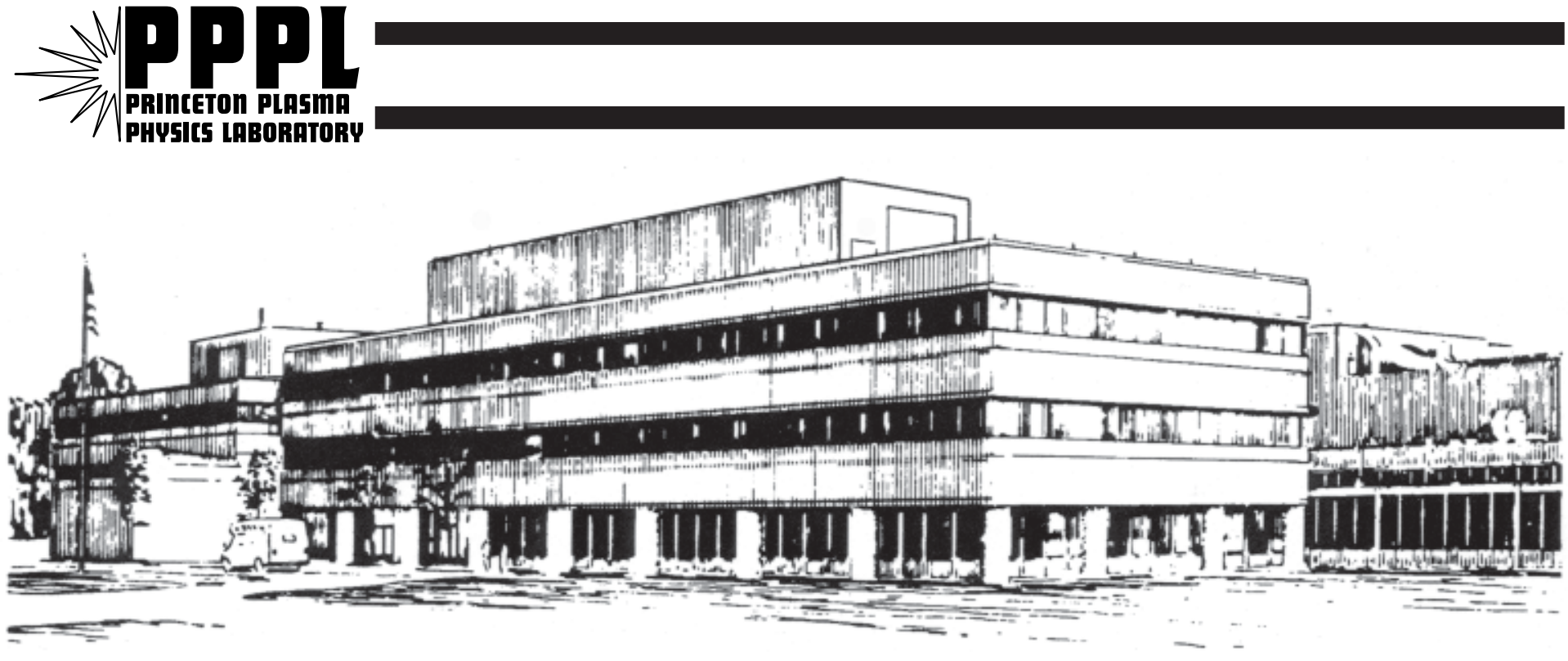

PRINCETON PLASMA PHYSICS LABORATORY PRINCETON UNIVERSITY, PRINCETON, NEW JERSEY 


\section{PPPL Reports Disclaimer}

This report was prepared as an account of work sponsored by an agency of the United States Government. Neither the United States Government nor any agency thereof, nor any of their employees, makes any warranty, express or implied, or assumes any legal liability or responsibility for the accuracy, completeness, or usefulness of any information, apparatus, product, or process disclosed, or represents that its use would not infringe privately owned rights. Reference herein to any specific commercial product, process, or service by trade name, trademark, manufacturer, or otherwise, does not necessarily constitute or imply its endorsement, recommendation, or favoring by the United States Government or any agency thereof. The views and opinions of authors expressed herein do not necessarily state or reflect those of the United States Government or any agency thereof.

\section{Availability}

This report is posted on the U.S. Department of Energy's Princeton Plasma Physics Laboratory Publications and Reports web site in Fiscal Year 2003. The home page for PPPL Reports and Publications is: http://www.pppl.gov/pub_report/

DOE and DOE Contractors can obtain copies of this report from:

U.S. Department of Energy

Office of Scientific and Technical Information

DOE Technical Information Services (DTIS)

P.O. Box 62

Oak Ridge, TN 37831

Telephone: (865) 576-8401

Fax: (865) 576-5728

Email: reports@adonis.osti.gov

This report is available to the general public from:

National Technical Information Service

U.S. Department of Commerce

5285 Port Royal Road

Springfield, VA 22161

Telephone: $1-800-553-6847$ or

(703) $605-6000$

Fax: (703) 321-8547

Internet: http://www.ntis.gov/ordering.htm 


\title{
Transport in Auxiliary Heated NSTX Discharges*
}

\author{
B.P. LeBlanc ${ }^{1}$, M.G. Bell ${ }^{1}$, R.E. Bell ${ }^{1}$, M.L. Bitter ${ }^{1}$, C. Bourdelle ${ }^{2}$, D.A. Gates ${ }^{1}$,
} S.M. Kaye ${ }^{1}$, R. Maingi ${ }^{3}$, J.E. Menard ${ }^{1}$, D. Mueller ${ }^{1}, \underline{\text { M. Ono }}{ }^{1}$, S.F. Paul ${ }^{1}$, M.H. Redi ${ }^{1}$, A.L. Roquemore ${ }^{1}$, A. Rosenberg ${ }^{1}$, S.A. Sabbagh ${ }^{4}$, D. Stutman ${ }^{5}$, E.J. Synakowski ${ }^{1}$, V.A. Soukhanovskii ${ }^{1}$, J.R.Wilson ${ }^{1}$

${ }^{1}$ Princeton Plasma Physics Laboratory, Princeton, New Jersey 08543, USA

${ }^{2}$ DRFC, CEA, Cadarache, Saint-Paul lez Durance cedex, France

${ }^{3}$ Oak Ridge National Laboratory, Oak Ridge, Tennessee 37830, USA

${ }^{4}$ Department of Applied Physics, Columbia University New York, NY 10027, USA

${ }^{5}$ Johns Hopkins University, Baltimore, Maryland, USA

The NSTX spherical torus (ST) provides a unique platform to investigate magnetic confinement in auxiliary heated plasmas at low aspect ratio. Auxiliary power is routinely coupled to ohmically heated plasmas by deuterium neutral beam injection (NBI) and by high-harmonic fast waves (HHFW) launch. While theory predicts both techniques to preferentially heat electrons, experiment reveals $T_{e}>T_{i}$ during HHFW, but $T_{e}<T_{i}$ during NBI. In the following we present the experimental data and the results of transport analyses.

Figure 1 displays four time evolution panels for a deuterium high power NBI heated discharge lasting beyond $0.55 \mathrm{~s}$. In the top panel we see that the flattop of the $0.9 \mathrm{MA}$ plasma current starts at $0.18 \mathrm{~s}$. The plasma has a lower single null configuration (LSN) for

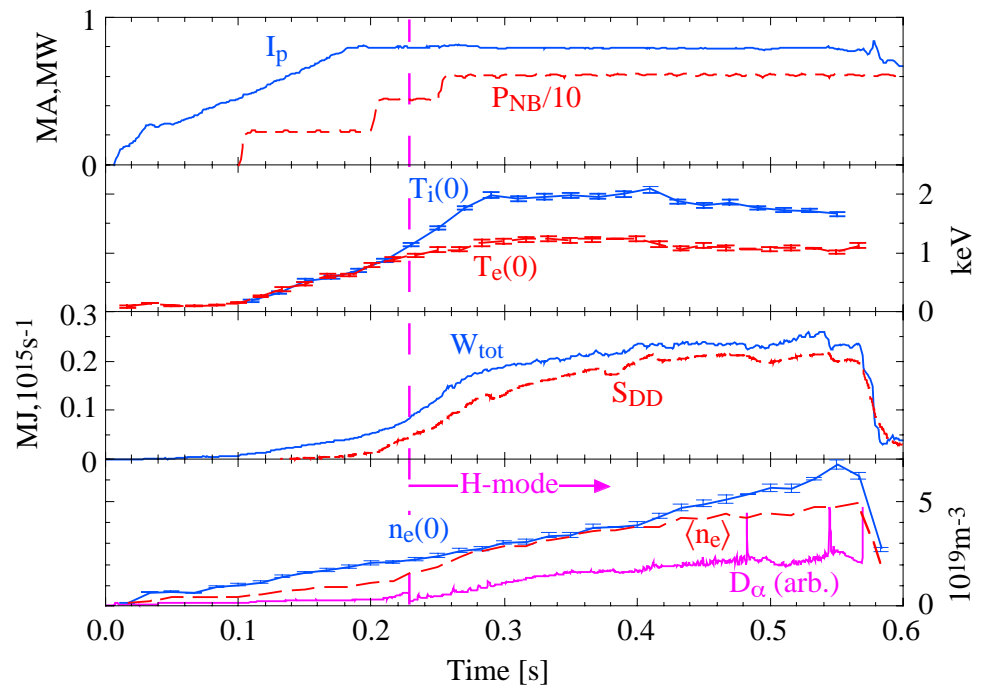

Figure 1: Time evolution of a high power NBI heated plasmas. H-mode transition marked with a dotted line. the time of interest. Three neutral beam sources are staggered with respective onset times of $0.1,0.2$ and $0.25 \mathrm{~s}$; NBI lasts until the end of the discharge. The injection energy ranges from $80 \mathrm{keV}$ to $95 \mathrm{keV}$. $\beta_{T}$ reaches $15 \%$ and the energy confinement time, $\tau_{E}$, is $\approx 0.04 \mathrm{~s}$. A vertical dotted line marks the $\mathrm{H}$-mode transition time, which can be seen on the $D_{\alpha}$ trace 

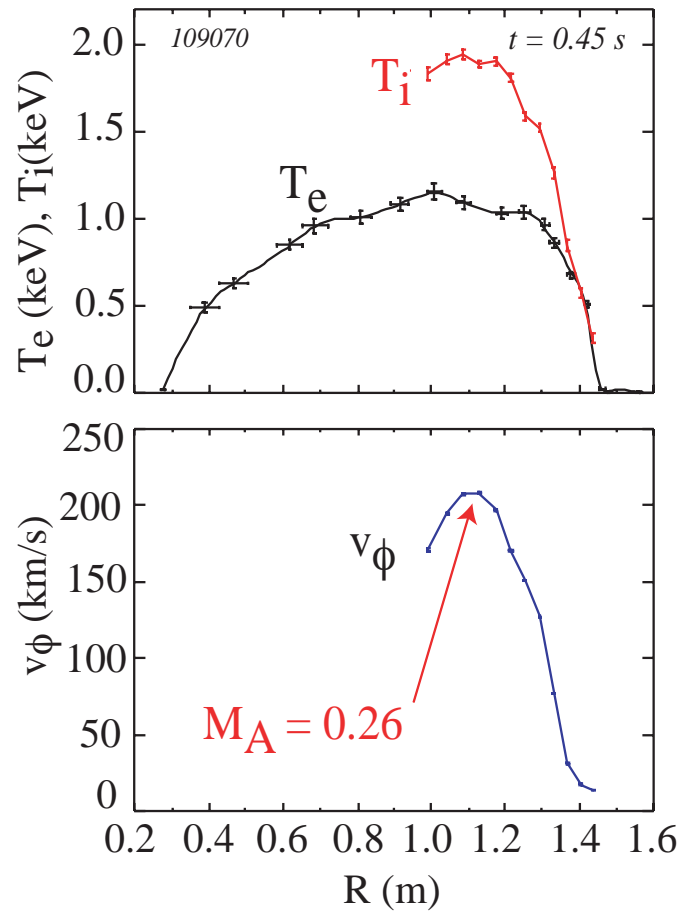

Figure 2: Kinetic profile during NBI. (a) Overlay of $T_{e}$ and $T_{i}$ profile $s$. (b) Profile of $v_{\phi}$. The the Alfvén Mach number reaches $M_{A}=0.26$ in the plasma core. (bottom panel). The central ion temperature, $T_{i 0}$, and electron temperature, $T_{e 0}$, are equal during the early phase of auxiliary heating. But for times greater than $0.22 \mathrm{~s}, T_{i 0}$ increases over $T_{e 0}$ and remains greater until the end of the discharge. A small drop of $T_{i 0}$ at $\approx 0.42 \mathrm{~s}$ is echoed by $T_{e 0}$. The $T_{i}(R), T_{e}(R)$ and toroidal velocity $v_{\phi}(R)$ profiles shown in Fig. 2 correspond to $t=0.45 \mathrm{~s}$ of this discharge. While there is good agreement between $T_{e}$ and $T_{i}$ at the edge, we see that $T_{i}>T_{e}$ over a wide section of the plasma column. Since the beam energy is typically many times larger than the 1-2 keV electron temperature, one would expect from classical slowing down physics of fast particles that most $(\approx 2 / 3)$ of the neutral beam power be deposited into the electron population. The experimental observation that $T_{i}$ is greater than $T_{e}$ during NBI despite the expected preferential electron heating suggests that the ion confinement is much better than that of the electrons. The third panel shows global

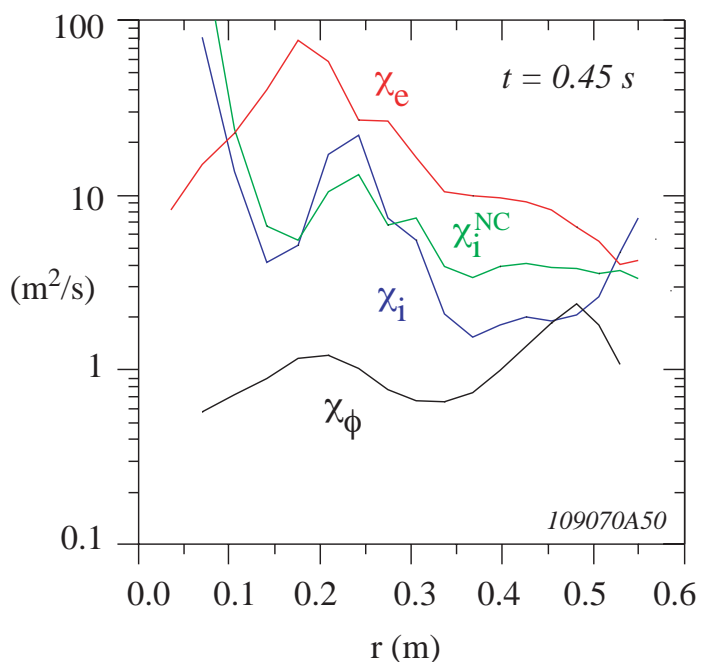

Figure 3: Experimental diffusivities during high power NBI heating: electron thermal, $\chi_{\mathrm{e}}$, ion thermal, $\chi_{\mathrm{i}}$, and momentum, $\chi_{\phi}$. Neoclassical calculation of ion thermal diffusivity, $\chi_{i}^{N C}$. measurements stored energy and neutron production rate, which are well reproduced in TRANSP analyses. The effects of the $\mathrm{H}$ mode are seen in the bottom panel where the central density, $n_{e 0}$ and the volume average density $\left\langle n_{e}\right\rangle$ are displayed. One sees that $n_{e 0} \approx\left\langle n_{e}\right\rangle$ from $0.25 \mathrm{~s}$ to $0.40 \mathrm{~s}$, corresponding to a phase where $n_{e}(R)$ profile builds up "ears" in the edge regions. Later on $n_{e 0}$ becomes greater than $\left\langle n_{e}\right\rangle$ as the center of the density profile fills in. More details about H-mode plasmas in NSTX can be found elsewhere [1]. Figure 3 shows profiles of the power and momentum balance diffusivities extracted from TRANSP analysis at $t=0.45 \mathrm{~s}$. 


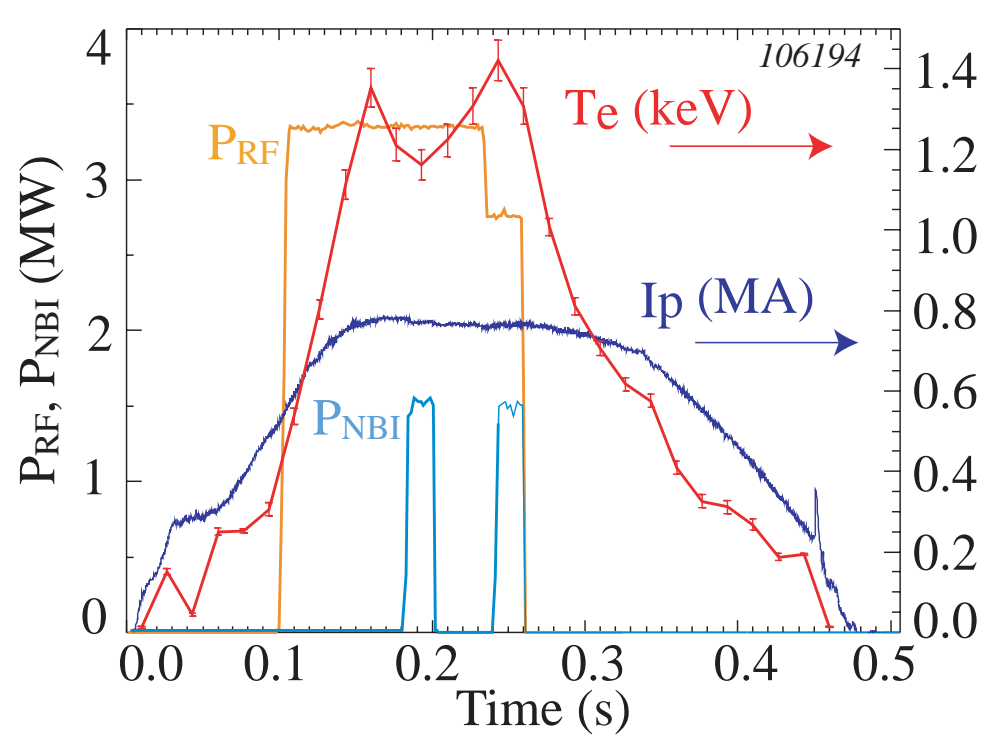

Figure 4: HHFW heating in 0.5 MA, 0.45 T, He plasma. $T_{e 0}$ rises rapidly $101.3 \mathrm{keV}$ in response to HHFW power onset. Two short NBI pulse are use for $T_{i}$ measurement.
The momentum diffusivity $\chi_{\phi}$ is the lowest in magnitude, hovering slightly below $1 \mathrm{~m}^{2} / \mathrm{s}$ in the core region and increases towards the edge up to slightly higher than $2 \mathrm{~m}^{2} / \mathrm{s}$. The $\chi_{i}$ profile has a different behavior, being the largest in the core region and lowest in the edge region. The neoclassical $\chi_{i}^{N C}$ prediction from the NCLASS code [2] follows the shape of $\chi_{i}$ over the whole profile. This is partially due to the fact that $\chi_{i}^{N C}$

is computed using the neoclassical ion thermal flux from NCLASS and the measured local gradient and density. One notes that $\chi_{i} \approx \chi_{i}^{N C}$ in the core region, while $\chi_{i}<\chi_{i}^{N C}$ in the outer region. The electron thermal confinement is poor, with large $\chi_{e}$ values reflecting the flattening of the core $T_{e}$ profile seen in Fig. 2. The overall $\chi_{e}(R)$ shape is also unusual, being lower at the edge than at in the core. These results support the inference that the ion confinement is superior to that of the electrons in NSTX NBI discharges. A micro-stability analysis can be found elsewhere [3].

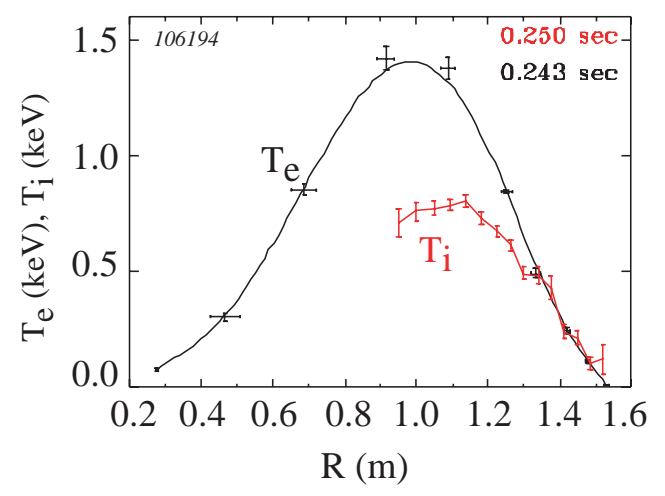

Figure 5: Measured $T_{e}$ and $T_{i}$ profiles during second NBI diagnostic pulse. $T_{e}$ is roughly twice $T_{i}$ in core region. $T_{e} \approx T_{i}$ in edge region.
HHFW heating is an important auxiliary heating system that complements NBI. The antenna array comprises 12 current carrying elements driven by transmitters operating at $30 \mathrm{MHz}$. In the present case the launch spectrum is undirected and characterized by $k_{/ /}$ $=14 \mathrm{~m}^{1}$. The application of HHFW power is an effective means of bulk electron heating.

One can see in Fig. 4 the temporal evolution of relevant plasma parameters of a LSN helium discharge undergoing HHFW heating. The toroidal field is $0.45 \mathrm{~T}$ and the 


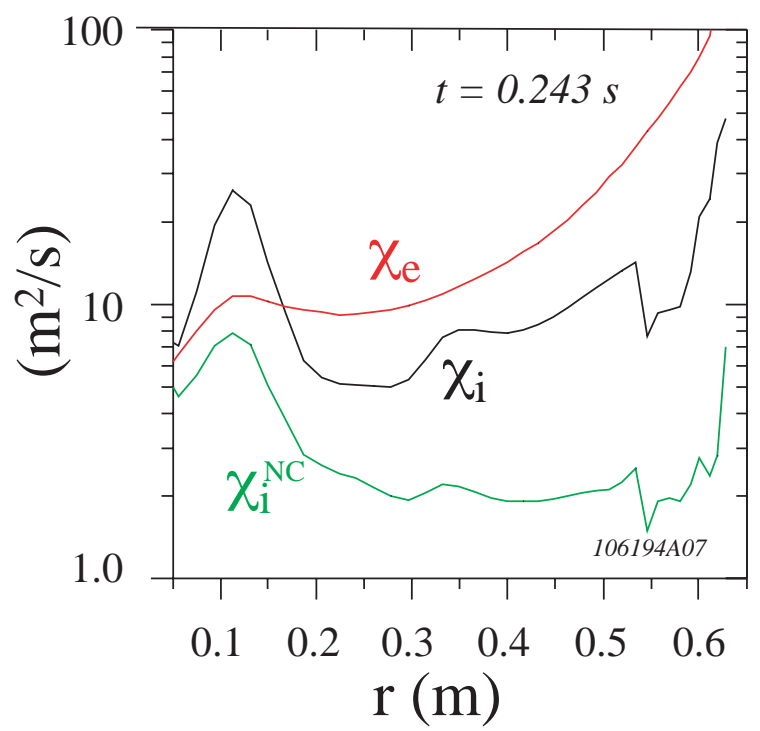

Figure 6: Experimental thermal diffusivity profiles against minor radius $r$ during HHFW heating: electron thermal, $\chi_{e}$, and ion thermal, $\chi_{i}$. Neoclassical calculation of ion thermal diffusivity, $\chi_{i}^{N C}$.

plasma current 0.8 MA. HHFW power reaching 3.3 $\mathrm{MW}$ is applied during the 0.1 0.26 s time interval. Following the HHFW power onset, a rapid increase of the central electron temperature, $T_{e 0}$, rising from $0.3 \mathrm{keV}$ to $1.3 \mathrm{keV}$ in $0.06 \mathrm{~s}$. $\beta_{T}$ reaches $4.5 \%$ and $\tau_{E} \approx 0.014 \mathrm{~s}$. The low $T_{e 0}$ seen at $t$ $\approx 0.045 \mathrm{~s}$ is caused by a radial shift of the plasma column. Two NBI short pulses were injected to measure the $T_{i}$ profile by charge exchange recombination spectroscopy. Figure 5 shows an overlay of the $T_{i}$ and $T_{e}$ profiles corresponding to the second beam blip. We find again good agreement between $T_{i}$ and $T_{e}$ in the edge region. In the central region, $T_{e}$ reaches $1.4 \mathrm{keV}$, while $T_{i}$ remains at $0.8 \mathrm{keV}$, as one would expect under this condition of electron heating. A TRANSP analysis can be made by making use of the HPRT[4] code for the computation of the HHFW power deposition by ray tracing. Such a calculation was made for a time within the second NBI diagnostic pulse. Most of the HHFW power is absorbed by the electrons, over a wide profile that peaks in the center. Only a very small amount of power is absorbed by the thermal ions, but some power is absorbed by the fast ions during NBI. For the purpose of this analysis, the power absorbed by the fast ions is divided evenly between thermal ions and electrons. In absence of NBI, the electrons absorb essentially all the HHFW power. One can see in Fig. 6 profiles of the thermal diffusivities at $t=0.243$ s corresponding to the time shown in Fig. 5. Contrary to what was seen in the high-power NBI case shown earlier, one sees that $\chi_{i}>\chi_{i}^{N C}$. Electron thermal transport remains the leading loss mechanism. The thermal diffusivities $\chi_{i}$ and $\chi_{e}$ bare profiles that are lower at the center and larger near the edge.

*This work is supported by U.S. DOE contract DE-AC02-76CH03073.

1 Maingi, R, et al., "H-mode Research in NSTX" submitted to Nuclear Fusion.

2 Houlberg, W.A., Shaing K.C., Hirshman S.P., Zarnstorff M.C., Phys. Plasmas 4, 3230 (1997)

3 Redi. M.H., at this conference

4 Menard J., Majeski R., Kaita R., Ono M., Munsat T., Phys. Plasmas, 6 (1999) 2002. 


\section{External Distribution}

Plasma Research Laboratory, Australian National University, Australia

Professor I.R. Jones, Flinders University, Australia

Professor João Canalle, Instituto de Fisica DEQ/IF - UERJ, Brazil

Mr. Gerson O. Ludwig, Instituto Nacional de Pesquisas, Brazil

Dr. P.H. Sakanaka, Instituto Fisica, Brazil

The Librarian, Culham Laboratory, England

Mrs. S.A. Hutchinson, JET Library, England

Professor M.N. Bussac, Ecole Polytechnique, France

Librarian, Max-Planck-Institut für Plasmaphysik, Germany

Jolan Moldvai, Reports Library, Hungarian Academy of Sciences, Central Research Institute for Physics, Hungary

Dr. P. Kaw, Institute for Plasma Research, India

Ms. P.J. Pathak, Librarian, Institute for Plasma Research, India

Ms. Clelia De Palo, Associazione EURATOM-ENEA, Italy

Dr. G. Grosso, Instituto di Fisica del Plasma, Italy

Librarian, Naka Fusion Research Establishment, JAERI, Japan

Library, Laboratory for Complex Energy Processes, Institute for Advanced Study, Kyoto University, Japan

Research Information Center, National Institute for Fusion Science, Japan

Dr. O. Mitarai, Kyushu Tokai University, Japan

Dr. Jiangang Li, Institute of Plasma Physics, Chinese Academy of Sciences, People's Republic of China

Professor Yuping Huo, School of Physical Science and Technology, People's Republic of China

Library, Academia Sinica, Institute of Plasma Physics, People's Republic of China

Librarian, Institute of Physics, Chinese Academy of Sciences, People's Republic of China

Dr. S. Mirnov, TRINITI, Troitsk, Russian Federation, Russia

Dr. V.S. Strelkov, Kurchatov Institute, Russian Federation, Russia

Professor Peter Lukac, Katedra Fyziky Plazmy MFF UK, Mlynska dolina F-2, Komenskeho Univerzita, SK-842 15 Bratislava, Slovakia

Dr. G.S. Lee, Korea Basic Science Institute, South Korea

Institute for Plasma Research, University of Maryland, USA

Librarian, Fusion Energy Division, Oak Ridge National Laboratory, USA

Librarian, Institute of Fusion Studies, University of Texas, USA

Librarian, Magnetic Fusion Program, Lawrence Livermore National Laboratory, USA

Library, General Atomics, USA

Plasma Physics Group, Fusion Energy Research Program, University of California at San Diego, USA

Plasma Physics Library, Columbia University, USA

Alkesh Punjabi, Center for Fusion Research and Training, Hampton University, USA

Dr. W.M. Stacey, Fusion Research Center, Georgia Institute of Technology, USA

Dr. John Willis, U.S. Department of Energy, Office of Fusion Energy Sciences, USA

Mr. Paul H. Wright, Indianapolis, Indiana, USA 
The Princeton Plasma Physics Laboratory is operated by Princeton University under contract with the U.S. Department of Energy.

\author{
Information Services \\ Princeton Plasma Physics Laboratory \\ P.O. Box 451 \\ Princeton, NJ 08543
}

Phone: 609-243-2750

Fax: 609-243-2751

e-mail: pppl_info@pppl.gov

Internet Address: http://www.pppl.gov 